\title{
PERFURAÇÃO ESPONTÂNEA DE DUCTO HEPÁTICO COMUM
}

\author{
SPONTANEUS COMMON BILE DUCT PERFORATION
}

Carlos Eduardo Barbosa Ponte ${ }^{1}$; Naésio Costa Pereira²; José Huygens Parente Garcia, TCBC-CE

\section{INTRODUÇÃO}

Em adultos, as perfurações do ducto hepático comum (DHC) são geralmente descritas após procedimentos invasivos. ${ }^{1}$ As perfurações espontâneas do DHC são raras, sendo mais comuns em neonatos que em adultos. ${ }^{2}$ Os autores apresentam o caso de uma paciente adulta com quadro de abdome agudo causado por perfuração espontânea de ducto hepático comum.

\section{RELATO DO CASO}

Paciente de 24 anos do sexo feminino, deu entrada no serviço de emergência referindo dor intensa há cinco dias na região epigástrica sem irradiação, vômitos, anúria e constipação há três dias. Ao exame, o abdome encontrava-se distendido e com sinais de irritação peritoneal. A paciente tem história patológica pregressa de dor pós-prandial em região epigástrica, que cedia com medicamentos. A história familiar revela que a mãe e três tios maternos foram submetidos à colecistectomia por litíase biliar. Ultra-sonografia mostrou líquido livre na cavidade abdominal em grande quantidade, sem evidências de colelitíase.

Com esse quadro de abdome agudo foi indicada laparotomia exploradora que revelou coleperitônio de aproximadamente $1000 \mathrm{ml}$ com dilatação e perfuração de ducto hepático comum. Não havia cálculo no colédoco. Foi realizada colecistectomia e coledocoplastia com aposição de dreno de Kehr em ducto hepático comum e dreno de Penrose em leito hepático. Evoluiu bem e teve alta no $10^{\circ}$ dia pós-operatório (PO). O dreno de Kehr foi retirado ambulatorialmente após colangiografia de controle no $17^{\circ} \mathrm{PO}$ (Figura1).

\section{DISCUSSÃo}

A perfuração espontânea do ducto hepático comum é relatada com mais freqüência em neonatos, geralmente na junção com o ducto cístico, devido à sua maior fragilidade (Figura 2). O quadro clínico é de icterícia súbita, acolia fecal, aumento do volume abdominal com ascite e comprometimento do estado geral. A perfuração do DHC em grávidas está publicada na literatura, e a coledocolitíase è o provável fator

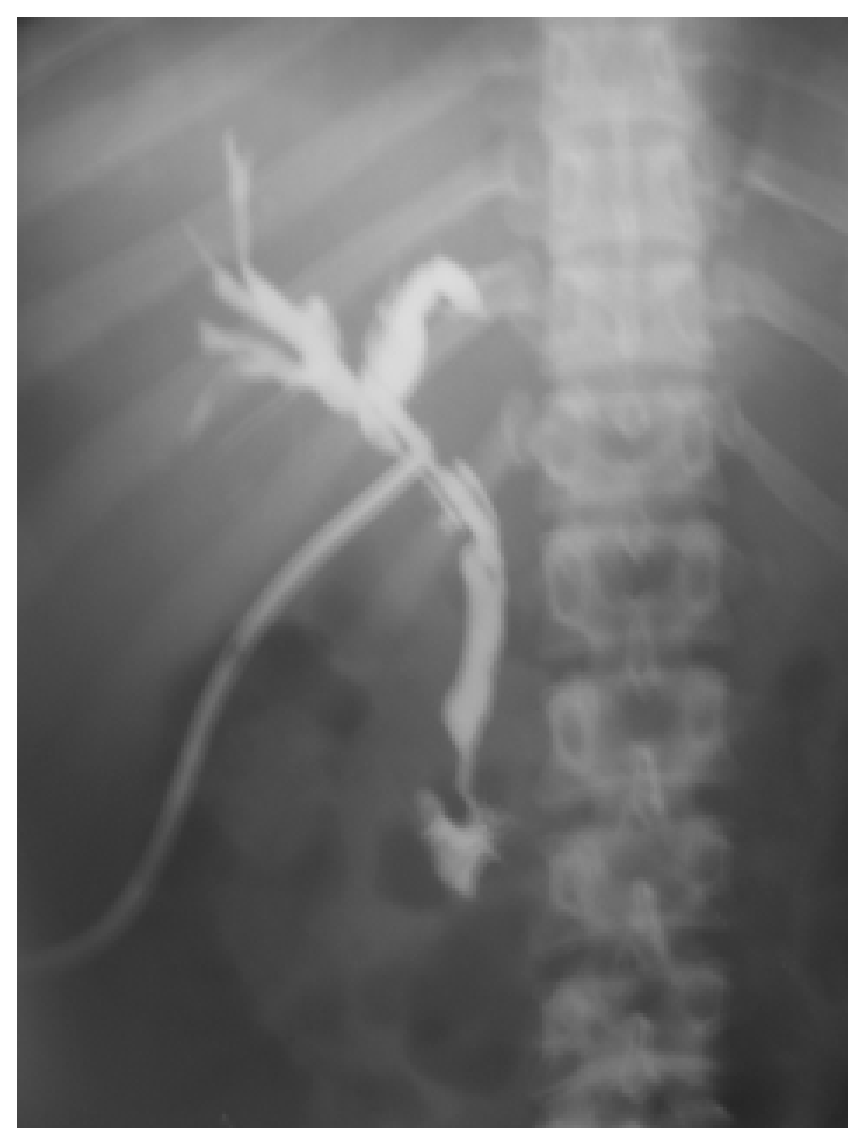

Figura 1 - Colangiografia pelo dreno de Kehr no $17^{\circ}$ dia de pósoperatório.

etiológico juntamente com o aumento da pressão na veia cava, devido às mudanças hemodinâmicas ${ }^{3,4}$.

Já em adultos, as perfurações se dão com mais freqüência após procedimentos invasivos, como colangiopacreatografia retrógrada endoscópica e cirurgias envolvendo as vias biliares. A perfuração espontânea do DHC é uma entidade rara com pouco mais de 40 casos semelhantes relatados ${ }^{2}$.

A obstrução causada pela coledocolitíase, que é a etiologia mais documentada, leva a um aumento da pressão intra-ductal levando à dilatação das vias biliares e à estase, o que promove infecção e trombose das veias intra-murais,

1. Médico formado pela Faculdade de Medicina da Universidade Federal do Ceará.

2. Residente de Cirurgia Geral do $2^{\circ}$ ano, no Instituto Dr. José Frota.

3. Professor titular da Faculdade de Medicina da Universidade Federal do Ceará, Mestre e Doutor em Farmacologia; Coordenador geral do Centro de Transplante Hepático do Ceará. 


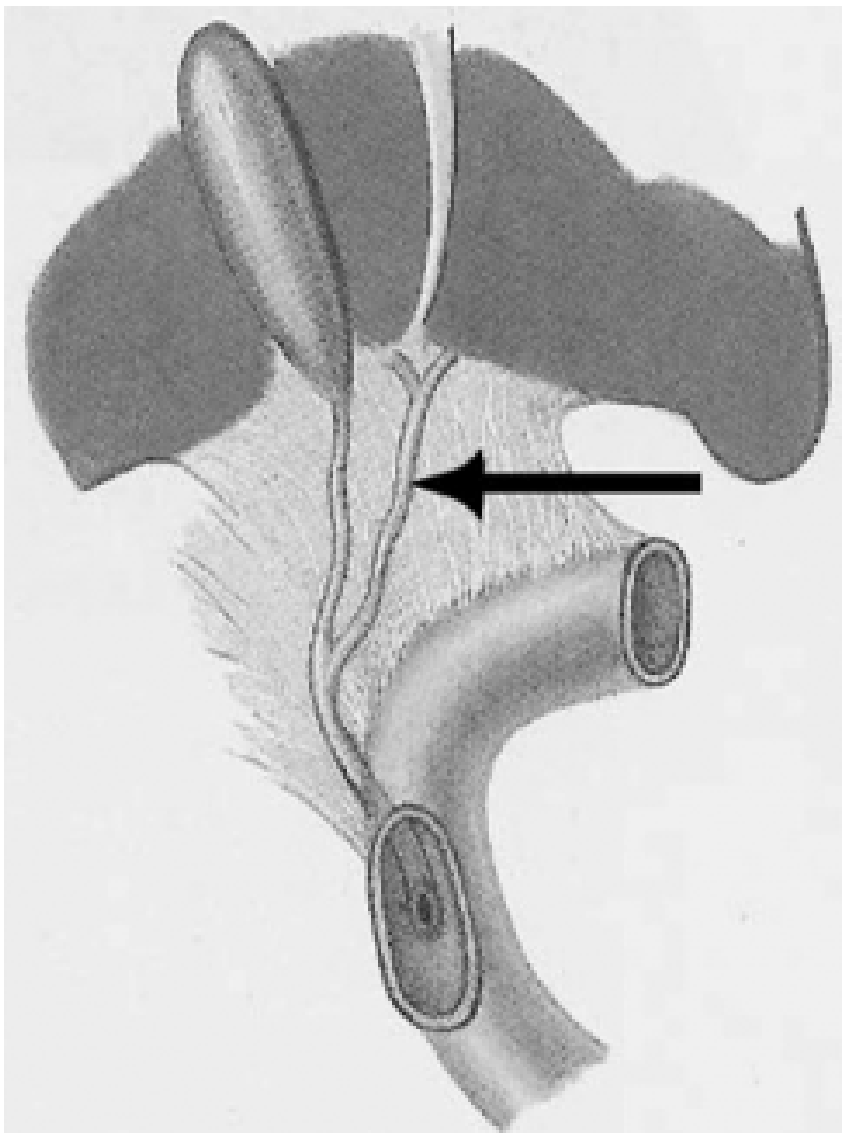

podendo evoluir para necrose e perfuração da parede do ducto. ${ }^{5}$ No caso apresentado, a paciente tinha uma história patológica pregressa e uma história familiar bastante favorável à litíase biliar, mas não foi encontrado cálculo nas vias biliares. Outras causas menos comuns são também relatadas na literatura, tais como: refluxo do suco pancreático ativado, fragilidade congênita da parede do DHC e divertículo infectado. ${ }^{1}$

O quadro clínico pode ser tanto insidioso como agudo. O primeiro é caracterizado por uma síndrome de obstrução das vias biliares, com distensão abdominal indolor, acolia fecal e icterícia progressiva. O segundo se manifesta como abdome agudo, com sinais de peritonite, vômitos, febre e distensão abdominal. $^{2}$

As lesões do DHC são raras, mas os cirurgiões que trabalham em grandes serviços de emergência devem estar preparados para fazer o diagnóstico diferencial e tomar a conduta adequada ${ }^{5}$.

Figura 2 - Local de maior freqüência de perfurações espontâneas $d a$ via biliar.

\begin{abstract}
Perforation of common bile duct $(C B D)$ is usually associated with invasive procedures. Spontaneous perforation is rare, and more often described in neonates. We report a case of a spontaneous perforation of CBD in an adult with a family history of cholelithiasis, but with no calculus found during exploration of the biliary tree. The patient was successfully treated by cholecystectomy and T-tube drainage of the CBD (Rev. Col. Bras. Cir. 2005; 32(3): 161-162).
\end{abstract}

Key-words: Common bile duct; Hepatic duct, common; Rupture, spontaneous: Adult.

\section{REFERÊNCIAS}

1. Hill NS, Colapinto ND. Spontaneous perforation of the common bile duct. Br J Surg. 1981;68(9):661-2

2. Rege SA, Lambe S, Sethi H, et al. Spontaneous common bile duct perforation in adult: a case report and review. Int Surg. 2002;87(2):81-2.

3. Balsarkar DJ, Subramaniyan P, Joshi MA. Spontaneous perforation of the common bile duct in pregnancy. Indian $\mathbf{J}$ Gastroenterol. 2001;20 (5):198-9

4. Paladugu R, Rau A, Schein M, et al. Spontaneous perforation of the hepatic duct in adults. Dig Surg.1998;15(5):417-20
5. Nomura T, Nikkumi $\mathrm{K}$, Kato $\mathrm{H}$, et al. Bile peritonitis due to spontaneous perforation of the common bile duct: report of a case. Surg Today. 1996;26(10):822-4

Endereço para correspondência:

Carlos Eduardo Barbosa Ponte

Av. Bezera de Menes 1172, apto 202

Bairro São Gerardo

CEP 60325-001

Fortaleza - CE 